\title{
Applications of 3D Planning, Plastic Materials and Additive Manufacturing in Functional Rehabilitations in the Head and Neck Surgery
}

\author{
GHEORGHE MUH LFAY ${ }^{1}$, ZOLTAN FABIAN2*, RADU NEAGOE ${ }^{3}$, KARIN URSULA HORVATH ${ }^{4}$ \\ ${ }^{1}$ University of Medicine and Pharmacy Targu Mures, Department of Otorhinolaryngology, 38 Gheorghe Marinescu Str., 540139, \\ Targu Mures, Romania \\ 2Mures County Emergency Hospital Targu Mures, Department of Oral and Maxillofacial Surgery, 50 Gheorghe Marinescu Str., \\ 540136 Targu Mures, Romania \\ 3University of Medicine and Pharmacy Targu Mures, Second Department of General Surgery, 38 Gheorghe Marinescu Str., 540139, \\ Targu Mures, Romania \\ ${ }^{4}$ University of Medicine and Pharmacy Targu Mures, Department of Ophthalmology, 38 Gheorghe Marinescu Str., 540139, Targu \\ Mures, Romania
}

\begin{abstract}
The developments in the biocompatible materials and additive manufacturing technologies gave birth to new possibilities in reconstructive surgery. In addition to revolutionizing the diagnostic possibilities, the modern medical imaging has led to the development of surgical planning software. Using these state-ofthe-art technologies, a new standard of care is rising with the spread of patient specific implants. Our view in studying and using these materials and technologies goes beyond their biocompatibility, focusing on the functional and esthetic impact of these restorations. Our aim is to show their potential benefits and pitfalls presenting a couple of posttraumatic and oncological application possibilities, focusing on the new presurgical planning, choice of materials and manufacturing technologies.
\end{abstract}

Keywords: plastic materials, patient specific implants, reconstructive surgery, quality of life, surgical techniques

The applications of new plastic biomaterials are rapidly gaining ground in medicine. One of the frontiers of this technological revolution in operating rooms are represented by the custom made patient specific implants (PSI) realized by means of additive manufacturing. This evolution is driven by both the research and development in the plastic materials as well as the advancements in the precision and cost effectiveness of additive manufacturing [1, 2]. As the computed tomography revolutionized the diagnostic tools in the clinicians' hands, 3D printing of these newly developed materials will change fundamentally how we will prepare and execute surgical maneuvers. These advancements have met the recent needs in different surgical specialties for new alloplastic implants or custom surgical tools to meet the requirements in reconstruction of the human skeleton $[3,4]$.

Paradigm shift in the surgical resection and reconstruction of high functionality tissues has been made since the dawn of microsurgery. Changes in reconstruction possibilities, longer life expectancy and higher quality of life (QoL) standards determined this evolution. Today, in the era of social networking, the aesthetic and functional demands towards surgical approaches are extremely high. The need for quick access to minimal invasive, safe and predictable surgical interventions had led to development of innovative imaging, planning, and navigation software.

Digital surgical planning and dynamic navigation revolutionized orthopedic, head and neck, craniomaxillofacial and neurosurgery. The new biocompatible materials, and manufacturing technologies made possible prosthetic reconstructions of unseen complexity.

However, the pure technological approach towards the human body represents a dead end. The surgeon must keep a very fine balance of the resected and conserved tissues in the functional subunits of the body, as today's non-biological prosthetics have limited or no active functionality. These passive implants need to be integrated into the active functional matrix of the body, in a way to preserve or improve biomechanical, and aesthetic parameters.

In the process of design, one can observe the differences between the points of views of bioengineers whom are prone to overrate the importance and usability of these implants, and of the surgeons whom may be skeptical to these new technological advancements. This duality of the team however is beneficial.

In traumatology and surgical oncology, the 3D printed models of the facial skeleton represent a great tool for studying and planning the surgery. Also, these models can be of value in cases where stock implants need to be adapted to the surface of the individual's bone in traumas, where osteosynthesis plates are adapted to the different surfaces of the skull and face.

These models are made today from plastic materials that are durable and sterilizable. One group of these materials are the resins. From the myriad of resins available one can choose the most suitable for every application. They have different properties, they can be transparent, steam sterilizable, highly durable, usually the more sophisticated the material is, the more cost will involve its use. But the simplicity of their usage and the availability of relatively cheap, high resolution 3D printers for in-house production, they represent a great value in medical facilities. They are used for printing surgical guides, anatomical models.

Polyamide is one of the most frequently used plastic for 3D model printing, its main medical applications are

\footnotetext{
*email:fabianzoli@gmail.com; Phone:0756050110
} 
surgical guides and splints which help executing the planned surgical maneuvers. The advantages of selective laser sintering (SLS) polyamides are the relatively low price of the powder, the steam sterilisability and good mechanical properties. Drawbacks of the polyamides are the high equipment costs, and the high porosity of the surface [5-8].

Applications of high-performance polymers like polyether-ether-ketone (PEEK) and poly-ether-ketone-ketone (PEKK) has been used since a while in manufacturing customized cranioplasty implants. Recently by the availability of additive manufacturing PEEK and PEKK has been proved to be a valuable material to replace metal implants, where load bearing function is a must. $[1,3,9$, 10]

Another great materials are the ultra-high molecular weight polyethylenes (UHMWPE). They have very good biocompatibility and excellent biomechanical properties. They main usage are joint prosthesis surfaces [11].

Application of this pioneer technology in the surgical theatre was recently introduced in our Head and Neck Surgery Clinic in Targu Mures. Focusing on the planning and manufacturing in the pre-surgical workflow, we reviewed some of these new methods, most of them already used by our team, helping our work in surgical oncology, traumatology and orthognathic surgery.

\section{Virtual surgical planning}

Virtual surgical planning has been an experimental tool, which was first used in the early 2000s. Due to the great benefits and cost effectiveness of this technology, a relatively quick adoption is in progress in many surgical specialties.
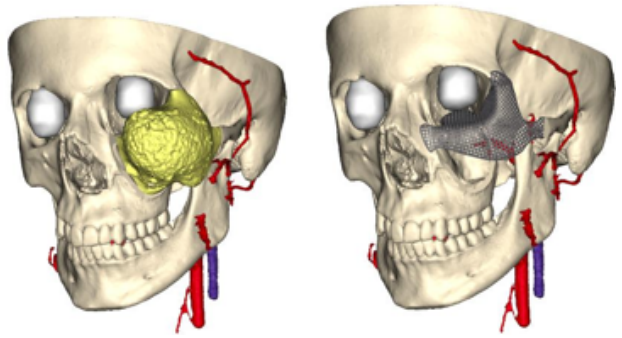

Fig. 1. Example of virtual surgical planning and reconstruction. A. Intraosseous tumor (yellow), B. Virtually resected tumor, and the reconstruction plate

\section{Surgical oncology}

Surgical oncology is a much demanding specialty regarding the reconstructions of the facial skeleton. Lege artis treatment of malign lesions involving soft tissues does not plead for a non-biologic reconstruction, but in case of benign bony tumors, the virtual planning with PSI manufacturing today is the treatment of choice, and its availability and cost effectiveness is improving every day. Before the availability of personalized solutions, the autologous bone grafts were the main solutions for extensive reconstructions in case of benign bony lesions. The major donor site for a thin lamina of bone was the external compacta of the calvaria. The donor site morbidity and the more predictable outcome has determined the surgeons to use more often personalized implants instead of bone grafts.

\section{Experimental part}

We present a reconstruction after the resection of the intraosseous benign tumor. Titanium implantwas designed by means of presurgical virtual planning mirroring the outline of the contralateral side of the facial skeleton. The implant was realized with selective laser melting procedure from titanium. This allowed us to perform the surgery without using autograft, thus eliminating the donor site morbidity, with an immediate successful result [12]. We implemented the necessary and sufficient design concept to restore the facial profile, thus avoiding possible issues of dehiscence or infections caused by an overextended implant design. 3D printed resin model of the skull was realized to help in visualizing and the defect in the planning procedure.

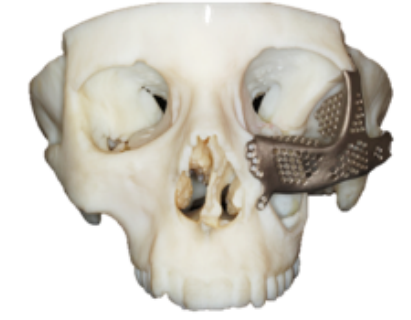

Fig. 2. 3D printed resin anatomical model of the skull of the patient, printed on Stratasys J 750 3D printer (Rehovot, Israel)

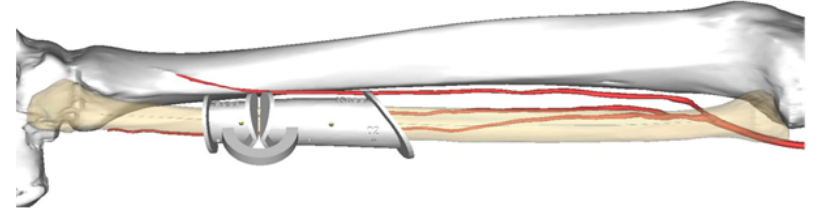

Fig. 3. Virtual model of the osteotomy guide used in harvesting a precise fibular graft, with embedded osteotomy planes to facilitate a perfect adaptation of the bone graft

In traumatology the benefits of the custom plates are invaluable, precise planning enables the calibration of functional parameters like the orbital volume or occlusion, thus eliminating the postoperative complications of diplopia or malocclusion.

We present a case of a posttraumatic deformity. The patient suffered displaced zygomatic bone-, lateral orbital wall and orbital floor fracture in a car accident. Primary reconstruction was hindered by the severely comminuted fracture. The calibration of the orbital volume was unachievable. We planned a secondary reconstruction using a custom-made 3D printed plate, which restored the orbital walls, calibrated the orbital volume and thus resolved the diplopia.
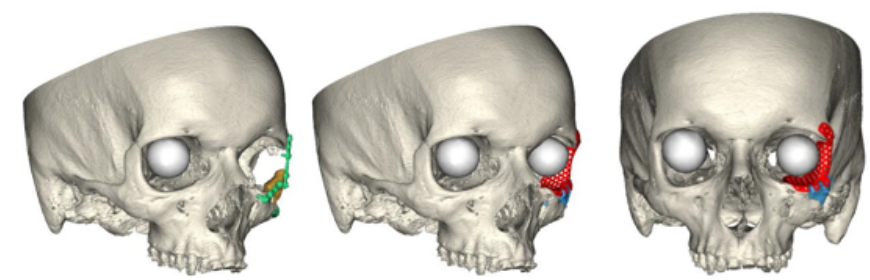

Fig. 4. Virtual model of the unsuccessful primary and the planned secondary reconstruction

\section{Results and discussions}

While these new plastic materials all meet the biocompatibility and biomechanical requirements, still, the fully functional integration into the body is unachievable with today's technology [13-15]. Raising the complexity of the implant in the desire to make it more functional may influence the overall outcome in a negative way, or even worse, may cause complications (e.g. dehiscence, infection) and may lead to total failure. This drawback guides our approach to avoid large monobloc designs, and to focus on reduced, minimal profiles, or in case of large defects to pursue a modular design. One of our recent unpublished research suggests that functional needs surpass esthetic needs. This is true mostly among elderly population, among whom the balance between the fleetingness of the beauty and the value of the functions 
has been moved in favor of functions which maintain a good QoL.

Some of the issues raised during the planning and treatment of the presented cases has guided us to a compromise approach. This approach assigns the values of the classical surgical principles to the new possibilities, thus avoiding the unconstrained implementation of the virtual surgery into the real life, keeping in mind our limits and the basic principles of medicine. As we emphasized earlier the applications of these implants and tools are related mainly to the bony lesions. The state of the art reconstructions for soft tissues remains the microvascular flaps. In order to surpass even the highest expectations in our treatments, we never hesitate combining all the techniques that is in our possession, like microvascular flaps, PSI, endoscopic surgery, navigation surgery.

\section{Conclusions}

Innovation and technology is and will be for a long time the next revolution in surgery that will push our endeavor for continuous development forward. This intrusion of technology into the surgical rooms gives us new possibilities. Like in everyday life the plastic materials had changed everything around us, even today the research and development in this area gives very important advancements. We cannot imagine industry, aeronautics, clothing etc. without them. How ever, the environmentalists are raising awareness of the inefficient recycling of plastic materials, so we need to use them with responsibility in our every-day life as well as in the surgical room.

Acknowledgments: This paper was published under the frame of the University of Medicine and Pharmacy Targu Mures, Romania, in an International Research Grant supported by MED-EL Wien, Austria (Financing Agreementno. FN48608h/1036/22.01.2016). The case reports are part of the PhD Thesis of the corresponding author who fulfilled requirements for the PhD degree in Medical Sciences at the same University.

\section{References}

1. TACK, P., VICTOR, J., GEMMEL, P., ANNEMANS, L., Biomed Eng Online, 15, no. 1, 2016, p. 115.

2. LEE, J.-Y., AN, J., CHUA, C.K., Applied Materials Today, 7, 2017, p. 120-133.

3. JAVAID, M., HALEEM, A., Alex J Med, 2017.

4.MIKOLAJEWSKA, E., MACKO, M., ZIARNECKI, L., STANCZAK, S., KAWALEC, P., MIKOLAJEWSKI, D., J ournal of Health Sciences, 4, no. 12,2014, p. 78-83

5. WONG, K.V., HERNANDEZ, A., 2012, no. 4, 2012, p. 1-10.

6. DIMITROV, D.M., de BEER, N., S Afr J Ind Eng, 25, no. 2, 2014, p. 112.

7. SALMORIA, G.V., LEITE, J.L., AHRENS, C.H., LAGO, A., PIRES, A.T.N., Polymer Testing, 26, no. 3, 2007, p. 361-368.

8. CAULFIELD, B., MCHUGH, P.E., LOHFELD, S., J ournal of Materials Processing Technology, 182, no. 1, 2007, p. 477-488.

9. KURTZ, S.M., DEVINE, J.N., Biomaterials, 28, 32, 2007, p. 4845-4869. 10. SHETTY, S., SHENOY, K., SHETTY, R., BHAT, V., RAGHER, M., Int J Recent Sci Res, 9, no. 4, 2018, p. 25724-25726.

11. WANG, A., SUN, D.C., STARK, C., DUMBLETON, J.H., Wear, 181, 1995, p. 241-249.

12. FABIAN, Z., SZABO, G., PETROVAN, C., HORVATH, K. U., BABICSAK, B., HUTTL, K., NEMETH, Z., BOGDAN, S., Oral Maxillofac Surg, 22, no. 2, 2018, p. 241-247.

13. SUCIU, B.A., HALMACIU, I., BUD, V., COPOTOIU, C., FODOR, D., TRAMBITAS, C., GODJ A, D., VUNVULEA, V., MOLNAR, C., BRINZANIUC, K., Mat Plast, 54, no. 4, 2017, p. 626-628.

14. TRAMBITAS, C., POP, T.S., TRAMBITAS MIRON, A.D., DOROBANTU, D.C., BRINZANIUC, K., Rev. Chim. (Bucharest), 68, no. 2, 2017, p. 387389.

15. BUDU, V.A., PANFILOIU, A., DECUSEARA, T., GULIGA, A., COSTACHE, A., SAVA, L., MISTRA, D., BULESCU, I., TUSALIU, M., The Scientific Bulletin of Electrical Engineering Faculty, 37, no. 2, 2017, p. 35-37.

Manuscript received: 18.06 .2018 